\title{
Perancangan Sistem Deteksi Dini Bencana Banjir Menggunakan Teknik Pengiriman DTMF Berbasis Modul RF 433 Mhz Dan Arduino
}

\author{
M. Zainal Arifin ${ }^{1)}$; Ema Utami ${ }^{2)}$; Eko Pramono ${ }^{3)}$ \\ ${ }^{1,2,3)}$ Program Studi Megister Teknik Informatika, Universitas Amikom Yogyakarta \\ 1) zainal.arifin@students.amikom.ac.id; ${ }^{2)}$ ema.u@amikom.ac.id; ${ }^{3)}$ eko.p@amikom.ac.id
}

\begin{abstract}
Flood is one of the unpredictable natural disasters, especially in the rainy season. There are many effects for many people, such as they lose their property and sometimes have many victims due to floods. So that, estimation of water level is important to detect the basic risk of flooding. In this study used the Water Level (TMA) in form of a short message technique which is can be sent from radio waves and river water level sensors. The value of the sensors to know the highest river water level itself, so it does not need signals, internet networks and also pulse for it. The final result of this study is the water level information which is normal status, standby I, standby II, standby III or standby IV.
\end{abstract}

Keywords: RF 433MHz, Flood, Arduino, Early Detection

\section{PENDAHULUAN}

Banjir adalah suatu kondisi dimana terjadi peningkatan debit air sungai sehingga meluap dan menggenangi daerah sekitarnya, dan menyebabkan berbagai kerugian bagi masyarakat yang terkena bencana ini [1].

Objek yang diukur dalam penelitian ini adalah Tinggi Muka Air (TMA). Semakin tinggi muka air tentu menjadi salah satu faktor yang menyebabkan potensi banjir. Sehingga upaya yang dirasa perlu adalah dengan adanya peringatan terlebih dahulu akan tinggi muka air akan dapat mengurangi nilai kerugian akibat bencana banjir tersebut.

Pada penelitian ini dengan menggunakan teknik DTMF yang dikirimkan melalui RF $433 \mathrm{MHz}$ diharapkan bisa menyelesaikan masalah pulsa dan internet, karena DTMF tidak membutuhkan sinyal dan jaringan internet serta tidak membutuhkan pulsa untuk penggunaannya sehingga dapat memberi informasi dini bencana banjir kepada instansi yang bertugas secara efektif dan maksimal.

\section{TINJAUAN PUSTAKA}

2.1 Penelitian Terkait

Penelitian Achmad Muzakky dkk pada tahun 2018 yang berisi tentang monitoring level air dengan level yang di informasikan adalah aman, siaga, awas dengan menggunakan water level sensor sebagai sensor untuk mendapatkan level ketinggian air dan Node MCU ESP8266 sebagai pemroses dan mengirimkan data secara nirkabel ke smartphone android menggunakan aplikasi BLYNK. Berdasarkan penelitian yang dilakukan hasil dari pengujiannya menuliskan respon dari alat dan sistem yang dibuat rata rata-rata respon aplikasi terhadap keadaan sebenarnya kurang dari 2 detik. Dan dalam kesimpulannya menuliskan bahwa informasi dapat di akses dengan syarat mendapat akses internet [2]. Penelitian Dedi Satria dkk pada tahun 2017 yang berisi tentang sistem pendeteksi dini bencana banjir dengan dengan informasi peringatan berbasis sms gateway, menggunakan sensor ultrasonic sebagai sensor untuk membaca level ketinggian air, Arduino uno sebagai mikrokontroller yang digunakan untuk memproses data dan modem gsm wavecom untuk output pengiriman informasi melalui sms yang dikirimkan ke masyarakat [3]. Teknik pengiriman pada pendeteksi banjir berbasis SMS (Short Message Service) dengan menggunakan teknik pengiriman ini memiliki kelemahan yaitu pada penggunaan pulsa dan jaringan isp yang digunakan [4]. Pada penelitian yang dilakukan dengan menggunakan RF $433 \mathrm{MHz}$ diharapkan bisa menyelesaikan masalah pulsa dan jaringan internet [5], karena modul RF tidak membutuhkan sinyal dan jaringan serta tidak membutuhkan pulsa untuk penggunaannya sehingga dapat memberi informasi dini bencana banjir kepada instansi yang bertugas secara efektif dan maksimal.

\subsection{DTMF}

DTMF merupakan metode pensinyalan yang digunakan untuk memutar nomor telepon pilihan oleh sebagian besar telepon. 
DTMF dialihsandikan berfungsi untuk mengubah sinyal DTMF ke data biner sehingga dapat digunakan oleh mikrokontroler ataupun rangkaian-rangkaian digital untuk diolah lebih lanjut [7].

Tabel 1. Frekuensi DTMF

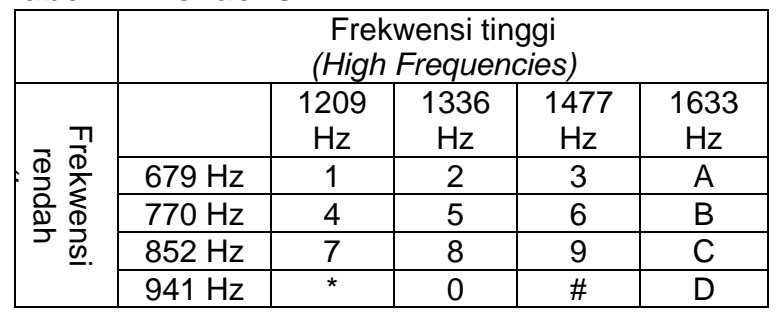

\subsection{MT8870}

MT8870 merupakan DTMF penerima yang menggunakan Teknik perhitungan digital untuk mendeteksi dan mengkodekan 16 pasang nada DTMF menjadi sebuah output kode 4 (empat) bit [7].

\subsection{Arduino Nano}

Arduino Nano adalah board Arduino berukuran kecil, lengkap, dan berbasis ATmega328 untuk Arduino Nano 3.0 atau ATmega168 untuk Arduino Nano 2.x. mempunyai kelebihan yang sama fungsional dengan Arduino Duemilanove, namun dalam paket yang berbeda. Kekurangannya tidak mempunyai DC power jack, dan hanya dengan kabel Mini-B USB standar. Arduino Nano didesain dan diproduksi oleh Gravitech [8].

\subsection{Arduino IDE}

Pemrograman Arduino menggunakan IDE (Integrated Development Environment) yang merupakan tool yang bermanfaat untuk menuliskan program (yang secara khusus dinamakan sketsa di Arduino), mengompilasinya, dan sekaligus mengunggahkannya ke papan Arduino. Software Arduino (IDE) menggunakan Bahasa yang sangat menyerupai Bahasa $C$ atau $\mathrm{C}++[9]$.

\section{METODE PENELITIAN}

3. 1 Jenis, Sifat dan Pendekatan Penelitian

Jenis, sifat dan pendekatan penelitian yang dilakukan pada penelitian ini adalah sebagai berikut:

\section{Jenis Penelitian Eksperimen}

Penelitian ini merupakan penelitian eksperimen yaitu: meneliti dan menerapkan pengiriman informasi menggunakan modul RF $433 \mathrm{MHz}$ pada pendeteksi dini bencana banjir.

\section{Pendekatan Penelitan Kuantitatif}

Pada penelitian ini menggunakan pendekatan kuantitatif yang nantinya hasil dari penelitian ini merupakan informasiinformasi berupa angka dari hasil eksperimen yang dilakukan. Pengumpulan data dilakukan melalui hasil eksperimen yang kemudian data tersebut menjadi hasil dari pengujian.

\subsection{Alur Penelitian}

Bagian ini berisi diagram alur langkah penelitian secara lengkap dan terinci termasuk di dalamnya tercermin algoritma, rute, pemodelan-pemodelan, desain, yang terkait dengan aspek perancangan sistem. Alur penelitian eksperimen pada penelitian ini ditunjukkan pada Gambar 1.

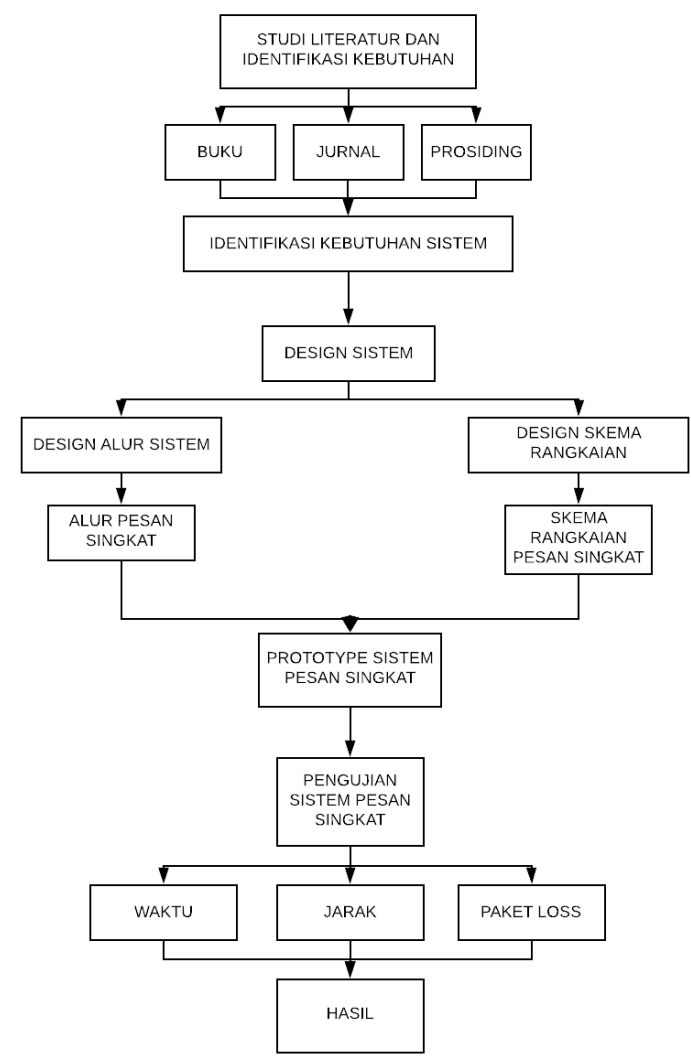

Gambar 1. Alur penelitian

Pada Gambar 1 adalah flowchart atau alur penelitian yang akan dilakukan pada penelitian ini, yaitu tahap pertama melakukan studi literatur dan identifikasi kebutuhan dari sistem yang akan dibuat, selanjutnya membuat desain atau rancangan sistem, membuat prototipe sistem, melakukan pengujian dan pengambilan data pengujian, serta membuat dokumentasi dan laporan penelitian. 


\section{HASIL DAN PEMBAHASAN}

4.1. Analisis Kebutuhan Fungsional

Dalam penelitian ini kebutuhan yang sangat mendasar adalah user agar mendapat informasi status ketinggian air sungai secara real time apakah kondisi air sungainya normal, siaga 1 , siaga 2 , siaga 3 dan siaga 4 .

4.2. Design sistem

Pada tahapan design sistem rencana sistem akan dibuat sesuai dengan design pada Gambar 2.

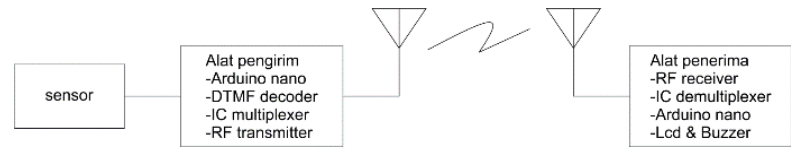

\section{Gambar 2. Design sistem teknik DTMF (dual tone multi frekuensi)}

Pada Gambar 2, sistem dibagi menjadi 2 alat yaitu alat pengirim (transmitter) dan alat penerima (receiver). Bagian desain alat pengirim komponen dan rangkaian ada pada Gambar 3, dan bagian alat penerima ada pada gambar 4 .

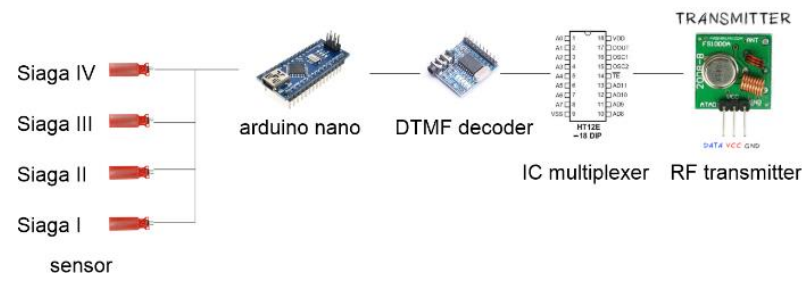

\section{Gambar 3. Rangkaian sistem alat pengirim}

Pada Gambar 3, komponen yang digunakan untuk membuat alat pengirim adalah sensor water level, Arduino uno, dan modul transmitter RF $433 \mathrm{MHz}$.

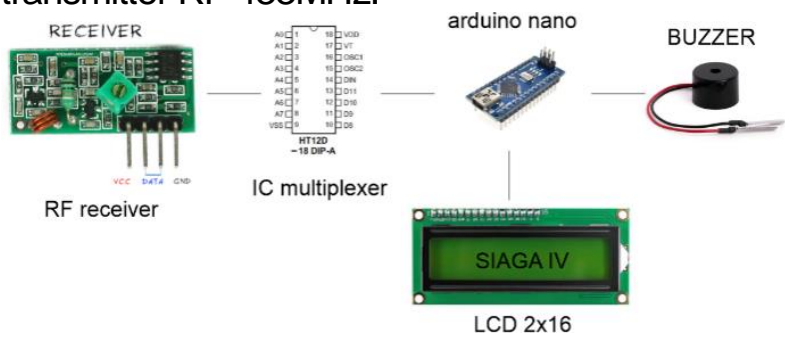

Gambar 4. Rangkaian sistem alat penerima

Pada Gambar 4, komponen yagn digunakan untuk membuat alat penerima informasi adalah modul receiver $\mathrm{RF} 433 \mathrm{MHz}$, Arduino uno, LCD 2x16 karakter, dan buzzer sebagai notifikasi apabila level ketinggian air "siaga IV".

\subsection{Perancangan sistem}

Pada tahapan perancangan, sistem akan dibuat seperti pada flowchart pada Gambar 5 dan Gambar 6 untuk prototipe sistem.

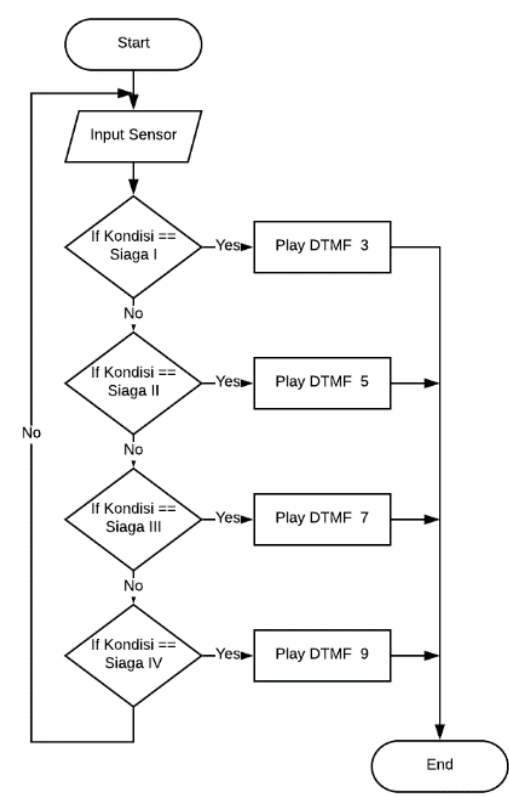

\section{Gambar 5. Flowchart alat pengirim}

Pada Gambar 5 merupakan flowchart proses dari rangkaian pengirim. Apabila input sensor 1 terendam air maka alat pengirim mengirimkan informasi "siaga I" melalui modul RF $433 \mathrm{MHz}$. apabila kondisi tidak ada input maka akan kembali ke proses membaca input, maka alat pengirim tidak akan mengirim informasi apapun.

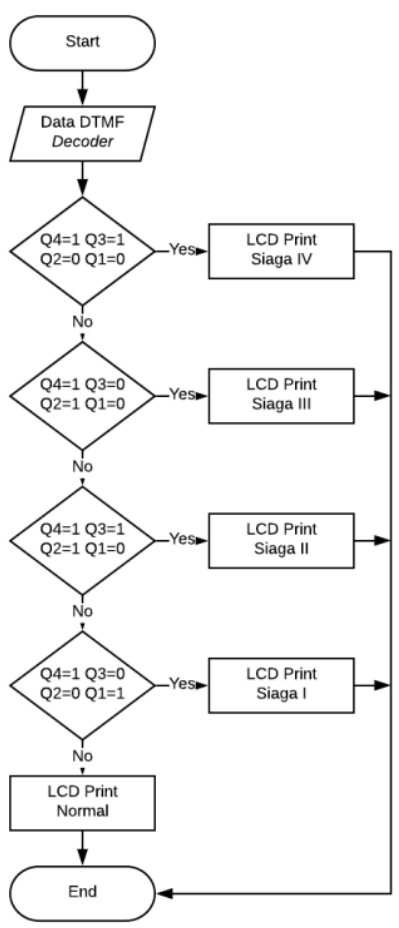

Gambar 6. Flowchart alat penerima 
Gambar 6 adalah gambar flowchart dari alat penerima, apabila dari modul receiver menerima informasi "siaga I" maka akan diproses dan menampilkan tulisan "siaga I" pada LCD, dan apabila alat penerima menerima informasi "siaga IV" akan menampilkan tulisan di LCD dan membunyikan buzzer peringatan.

Gambaran sistem dari perubahan ketinggian air sampai pada hasil Siaga I, Siaga 2, Siaga 3, dan Siaga 4, akan di ilustrasikan pada Gambar 7.

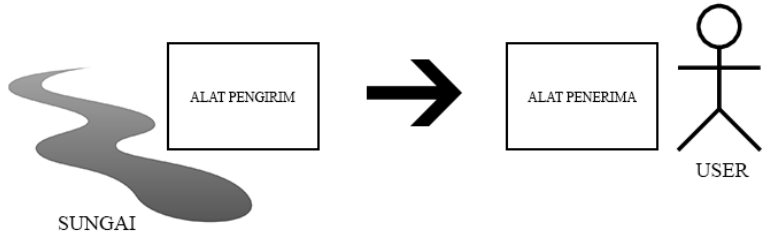

Gambar 7. Alur komunikasi antar alat pengirim dan penerima

Pada Gambar 7 menjelaskan bagaimana alat pengirim pada Gambar 3 mengukur ketinggian air sungai menggunakan sensor yang dipasangkan di sungai tersebut untuk membaca level ketinggian dari permukaan air sungai, selanjutnya informasi sensor diolah dan disandikan menggunakan teknik DTMF dan kemudian dikirimkan oleh alat pengirim melalui RF $433 \mathrm{MHz}$ transmitter ke RF $433 \mathrm{MHz}$ receiver yang ada pada alat penerima pada Gambar 4, kemudian informasi yang diterima $\mathrm{RF} 433 \mathrm{MHz}$ receiver akan diolah dan di decode yang sebelumnya berbentuk DTMF menjadi data yang menyandikan status ketinggian air Siaga 1, Siaga 2, Siaga 3, Siaga 4, atau Normal, untuk selanjutnya informasi ketinggian air di tampilkan ke LCD yang ada pada alat penerima Gambar 4 sehingga user atau petugas dapat mengetahui level ketinggian air.

\subsection{Pengujian}

Pengujian dilakukan untuk mengetahui apakah alat yang sudah di rancang telah memenuhi kebutuhan fungsional, hasil pengujian ditampilkan pada tabel 2 .

Tabel 2. Pengujian kebutuhan fungsionalitas.

\begin{tabular}{|c|l|c|c|c|}
\hline $\mathrm{N}$ & Kebutuhan & \multicolumn{2}{|c|}{ Pengujian } & \multirow{2}{\text{Rata-rata}}{$\begin{array}{c}\text { Delay } \\
\text { waktu }\end{array}$} \\
\cline { 3 - 4 } & Fungsional & Berhasil & Tidak & \\
\hline 1 & Normal & $\sqrt{ }$ & & - \\
\hline 2 & Siaga I & $\sqrt{ }$ & & 1.26 detik \\
\hline 3 & Siaga II & $\sqrt{ }$ & & 0.98 detik \\
\hline 4 & Siaga III & $\sqrt{ }$ & & 1.15 detik \\
\hline 5 & Siaga IV & $\sqrt{ }$ & & 0.65 detik \\
\hline
\end{tabular}

\section{PENUTUP}

Berdasarkan hasil pengujian, cara kerja dari penerapan teknik DTMF adalah dengan menyimbolkan kondisi sensor menjadi nada tinggi dan nada rendah sesuai dengan frekuensi pada Tabel 1 kemudian kedua frekuensi nada digabungkan dan dikirimkan melalui modul $\mathrm{RF} 433 \mathrm{MHz}$ alat pengirim ke modul RF $433 \mathrm{MHz}$ alat penerima, selanjutnya frequensi DTMF di ubah menjadi 4 data digital oleh DTMF decoder untuk menentukan informasi kondisi ketinggian air untuk ditampilkan pada LCD.

Pengiriman informasi status ketinggian air dengan menerapkan teknik DTMF yang dikirim menggunakan modul RF $433 \mathrm{MHz}$ sangat efektif karena tidak membutuhkan pulsa ataupun internet, sehingga masyarakat daerah aliran sungai bisa dengan cepat mendapatkan informasi ketinggian air apakah statusnya normal, siaga I, siaga II, siaga III atau siaga IV.

\section{DAFTAR PUSTAKA}

[1] Arief Andy Soebroto, Imam Cholissodin, Randy Cahya Wihandika, Maria Tenika Frestantiya, Ziya El Arief, "Prediksi Tinggi Muka Air (TMA) Untuk Mendeteksi Dini Bencana Banjir Menggunakan SVRTVWPSO," Jurnal Teknologi Informasi dan Ilmu Komputer (JTIIK), 2015.

[2] Muzakky, A., Nurhasi, A., Nurdiansyah, A., Wicaksana, G., Istiadi. (2018). Perancangan Sistem Deteksi Banjir Berbasis loT. Conference on Innovation and Application of Science and Technology (CIASTECH 2018).

[3] Satria, D., Yana, S., Munadi, R., Syahreza, S. (2017). Sistem Peringatan Dini Banjir Berbasis Sms Gateway Dan Mikrokontroler Arduino Uno. Seminar Nasional II USM. Vol. 1, Oktober 2017, 78-82

[4] IK Khisan, "Konsep Rancangan Pendeteksi Banjir Jarak Jauh Memanfaatkan Fasilitas Pesan Singkat (SMS)," Jurnal Teknik Elektro Undip, 2011.

[5] A Sumarudin, M. Yani, WP. Putra, F. Amri, P. Paskal "Sistem Pemantauan dan Peringatan Dini Potensi Banjir Sungai Cimanuk Berbasis Internet of Things (IoT)" Prosiding Industrial Research Workshop and National Seminar, 2017.

[6] Slameto, A.A., Pramono, E., Arifin, Z., (2019). Sistem Pendeteksi Dini Bencana 
Banjir Menggunakan Teknik DTMF (Dual Tone Multiple Frequency). Jurnal Teknologi Informasi Vol. XIV Nomor 2 Juni 2019.

[7] Windarto dan R Ristianti, "Aplikasi Kontrol Jarak Jauh Lampu dan Pagar Rumah dengan Teknologi Dual Tone Multi Frequency (DTMF)" Seminar Nasional Informatika (SNIf), 2017.

[8] Apri Junaidi, "Internet of Things, Sejarah, Teknologi dan Penerapannya: Review," Jurnal IImiah Teknologi Informasi Terapan, vol.1(3) hal. 62-66, 2015.

[9] Siswo Wardoyo, "Pengantar Mikrokontroler \& Aplikasi Pada Arduino," Graha IImu, 2015. 